\title{
Characterization and capacity dispersion of lithium-ion second-life batteries from electric vehicles
}

\author{
Elisa Braco, Idoia San Martín, Pablo Sanchis, Alfredo Ursúa \\ Department of Electrical, Electronic and Communication Engineering \\ Institute of Smart Cities \\ Public University of Navarre \\ Pamplona, Spain \\ elisa.braco@unavarra.es
}

\begin{abstract}
Nowadays, electric vehicle batteries reutilization is considered such as a feasible alternative to recycling, as it allows to benefit from their remaining energy and to enlarge their lifetime. Stationary applications as self-consumption or isolated systems support are examples of possible second life uses for these batteries. However, the modules that compose these batteries have very heterogeneous properties, and therefore condition their performance. This paper aims to characterize and analyze the existing capacity dispersion of Nissan Leaf modules that have reached the end of their lifetime on their original application and of new modules of this Electric Vehicle, in order to establish a comparison between them.
\end{abstract}

Keywords-Characterization, Electric vehicle, Energy storage, Lithium-ion battery, Renewable energy, Second life batteries.

\section{INTRODUCTION}

Environmental problems caused by fossil fuels are placing the Electric Vehicle (EV) as an alternative for sustainable mobility. As reported by the International Energy Agency, in 2017 the total number of EVs in the world reached 3.1 million [1]. According to this source, the figure will continue to grow until 1.2 billion by 2060 .

One of the most critical elements of EVs are their lithium-ion batteries. The performance of these batteries undermines with ageing, due to multiple factors, such as temperature, charge and discharge current rate or voltage operation limits, inter alia. For this reason, several regulations establish the end of their useful life when their capacity reaches an $80 \%$ of its initial value [2]. Nevertheless, some authors question this limit, and consider it overly conservative [3-4]. In this context, the first Nissan Leaf EVs were introduced in Japan and USA in 2011. According to their manufacturer, after 8 years their capacity is considered to have attained the $80 \%$ threshold [5]. Thus, the time has come for numerous batteries from these EVs to be withdrawn.

Being an important part of the EVs price, batteries reutilization emerges as a cost reduction alternative against other solutions as recycling. As reported by several authors, the salvage value of EVs batteries can lead to a reduction of their upfront costs up to a $20 \%$ [6,7]. It is in this background that the Second Life (SL) term appears, related to the post-EV use, in contrast to the so-called First Life (FL), in which they serve as energy storage device on the EV. The SL benefits from the remaining energy for less demanding applications, in which power and energy density are not as key as in EVs. There exist several examples of FL lithium-ion batteries used as storage systems on renewable energies applications [8-12]. In the case of SL batteries, one of the most promising uses is energy storage on residential photovoltaic installations [13]. Moreover, in the recent years, several OEM have supported demonstration projects with SL batteries [1416]. According to a report study by Bloomberg New Energy Finance, by $2025,95 \mathrm{GWh}$ will be available from EVs batteries and the SL market for stationary storage could reach $26 \mathrm{GWh}$ [17].

Today, there are many uncertainties with regard to economic viability on EV batteries reutilization [18, 19]. In principle, the cost of the SL batteries should be significantly lower than that of the new ones. The main drawbacks of SL with respect to FL batteries are their lower energy and power capacity, as well as their heterogeneity [4]. However, appropriate sizing, adapted to the specific SL application, can overcome limitations due to capacity and power fade. Furthermore, cells heterogeneity can be palliated with adequate association, and with specific control strategies, implemented in both Battery Management System (BMS) and power electronics converters, which are used to power conditioning [4].

Battery packs from EVs consist normally of series and/or parallel connected modules, in such a way that the desired voltage and capacity are achieved. These modules contain, in turn, series and/or parallel

We would like to acknowledge the support of the Spanish State Research Agency (AEI) and FEDER-UE under grants DPI201680641-R and DPI2016-80642-R and of Government of Navarra through research projects PI020 RENEWABLE STORAGE and 00111411-2018-000029 GERA. 
connected cells. In order to attain an adequate association, it is necessary to know the main characteristics of each cell or module that will be part of the SL battery pack, in particular their capacity, internal resistance and state of health. Cell or module associations with very different capacities and resistances can negatively affect the SL battery packs performance. For instance, there can be imprecisions on the calculations of the state of health algorithms [20]. Additionally, battery packs lifetime and therefore their economic viability will be considerably reduced. Moreover, the equalization processes required for the correct battery pack operation will be more frequent and longer, even perturbing its normal performance and efficiency. Finally, the underuse of some of the battery modules will undermine its energy and power density.

Considering the drawbacks of heterogeneous cells or modules association, this paper suggests the necessity of determining the dispersion of modules and/or cells previously used in EV. In addition, it stresses the need for cells and/or modules characterization, in order to have a successful association on SL battery packs. Consequently, the paper aims to analyze lithium-ion SL cells dispersion inside the module (intramodule) and between modules (inter-module), as well as to compare this dispersion with FL modules. For this purpose, the work is presented as follows: Section II describes the modules analyzed and the experimental procedure. Section III offers a detailed characterization of the modules and finally Section IV presents an intra-module and inter-module dispersion analysis for FL and SL modules, evaluating the difference of using FL or SL modules for battery pack assembling.

\section{EXPERIMENTAL SETUP}

\section{A. Module description}

The modules analyzed on this article were specially designed for EV, in particular for the Nissan Leaf model, and consist of manganese oxide/graphite $(\mathrm{LMO} / \mathrm{C})$ cells. Each module is composed of four pouch type cells, associated in two parallel-connected pairs in series $(2 s 2 p)$ [21]. The internal scheme of the modules is presented in Fig. 1a. The modules have three terminals: positive (R), middle point (W) and negative (B). Therefore, the superior pair cells and inferior pair cells are accessible, as it is shown in Fig. $1 b$. Table I presents module specifications.

The experimental study of this article has been carried out with 42 modules. 10 of which are of first life and the other 32 are of second life, hereafter called FL and SL modules respectively.

\section{B. Experimental procedure description}

The capacity test carried out consists of a sequence of five cycles of full constant current (CC)-constant voltage $(\mathrm{CV})$ charges until the maximum cell voltage and $\mathrm{CC}$ discharges until the minimum cell voltage. The current rate (C-Rate) on the $\mathrm{CC}$ phase is $\mathrm{C} / 3$, and the end current on the $\mathrm{CV}$ phase is set to $\mathrm{C} / 30$. $\mathrm{C}$ has been considered as $66 \mathrm{~A}$, value which corresponds to the rated capacity of the module (see Table I) in current units. Cell capacity is measured as the discharge capacity of the fifth cycle. All the modules are tested on the superior terminals (superior cells) and on the inferior terminals (inferior cells) at $25^{\circ} \mathrm{C} \pm 1{ }^{\circ} \mathrm{C}$.

Furthermore, the influence of current rate and temperature on a FL module and on a SL module is analyzed through a detailed characterization of their electrical behavior. For this purpose, several chargedischarge cycles are done at $5{ }^{\circ} \mathrm{C}, 25^{\circ} \mathrm{C}$ and $45^{\circ} \mathrm{C}$, varying the discharge current each two cycles. This way, three current rates are tested: $0.5 \mathrm{C}, 1 \mathrm{C}$ and $1.5 \mathrm{C}$. The test starts by setting the climatic chamber to the desired temperature. After, a two hours rest is set, so that cells reach thermal equilibrium. The cell is fully charged with the $\mathrm{CC}-\mathrm{CV}$ method until the maximum cell voltage at $0.5 \mathrm{C}$, with $\mathrm{C} / 30$ as end current on the $\mathrm{CV}$ phase. Discharges are $\mathrm{CC}$ until minimum voltage cell with the corresponding current rate.

a)

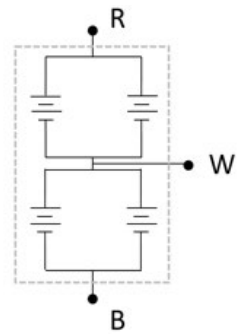

b)

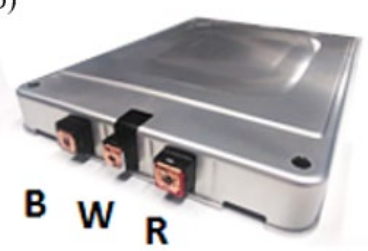

Fig. 1. a) Internal module scheme and b) Nissan Leaf module picture 
TABLE I. Module SpecificAtions

\begin{tabular}{|l|c|}
\hline & Module \\
\hline Nominal Voltage & $7.5 \mathrm{~V}$ \\
\hline Maximum Voltage & $8.3 \mathrm{~V}$ \\
\hline Minimum Voltage & $5 \mathrm{~V}$ \\
\hline Rated Capacity & $66 \mathrm{Ah}$ \\
\hline Length x Width x Thickness & $303 \mathrm{~mm} \times 223 \mathrm{~mm} \times 35 \mathrm{~mm}$ \\
\hline Mass & $3.85 \mathrm{~kg}$ \\
\hline
\end{tabular}

Fig. 2 shows the test bench used for the module characterization experiments. The test bench is formed by three Battery Testers, each of them having 16 channels which stand $5 \mathrm{~V}$ and $50 \mathrm{~A}$, and a voltage and current precision of $\pm 0.1 \%$ of the full scale in both cases. Moreover, two climatic chambers are part of the test bench, each of them having a temperature control precision of $\pm 0.5^{\circ} \mathrm{C}$.

\section{CHARACTERIZATION}

Capacity and power fade are two consequences of battery ageing which are strongly influenced by operating conditions. Several factors such as temperature, State of Charge (SOC), charge and discharge current and depth of discharge (DOD), etc. have great impact on batteries performance and aging. Therefore, in this section the influence of two of these parameters, temperature and discharge current, is analyzed on a FL module and on a SL module. Three discharge C-Rates $(0.5 \mathrm{C}, 1 \mathrm{C}$ and $1.5 \mathrm{C})$ and three operation temperatures $\left(5^{\circ} \mathrm{C}, 25^{\circ} \mathrm{C}\right.$ and $\left.45^{\circ} \mathrm{C}\right)$ are tested. First, the influence of these parameters on capacity is studied, and the impact of module degradation on their performance is subsequently analyzed for the different operating conditions tested.

\section{A. Influence of current and temperature on capacity measurements}

In this subsection, the impact of discharge current and temperature on capacity measurement is evaluated. Table II shows directly the capacity measurements obtained on the characterization test for the different temperatures and discharge currents. All the capacity data are in Ah.

Fig. 3 shows the results obtained according to the capacity test described in Section II, normalized with respect to the nominal capacity of the module $\left(C_{n}\right)$, for the three temperature levels $\left(5^{\circ} \mathrm{C}, 25^{\circ} \mathrm{C}\right.$ y $\left.45^{\circ} \mathrm{C}\right)$ and the three discharge current rates $(0.5 \mathrm{C}, 1 \mathrm{C}$ y $1.5 \mathrm{C})$ tested for the FL and the SL modules. Nominal capacity is measured at $25^{\circ} \mathrm{C}$ with a discharge current rate of $\mathrm{C} / 3$, obtaining $43.5 \mathrm{Ah}$ and $64.2 \mathrm{Ah}$ for the $\mathrm{SL}$ and FL modules respectively.

On the other hand, it is observed that the influence of discharge current on capacity measurements for a given temperature is especially important at $5{ }^{\circ} \mathrm{C}$. While at $45^{\circ} \mathrm{C}$ a maximum variation of $2.6 \%$ is obtained for the SL module, at $5{ }^{\circ} \mathrm{C}$, values differ up to a $17.8 \%$. The lowest result corresponds to $5{ }^{\circ} \mathrm{C}$, with a $1.4 \%$ as maximum variation. As in the previous case, FL module values obtained are similar for all the tested temperatures, with a $0.8 \%$ for $25^{\circ} \mathrm{C}$, a $1.1 \%$ for $45^{\circ} \mathrm{C}$ and a $1.3 \%$ in the case of $5{ }^{\circ} \mathrm{C}$.

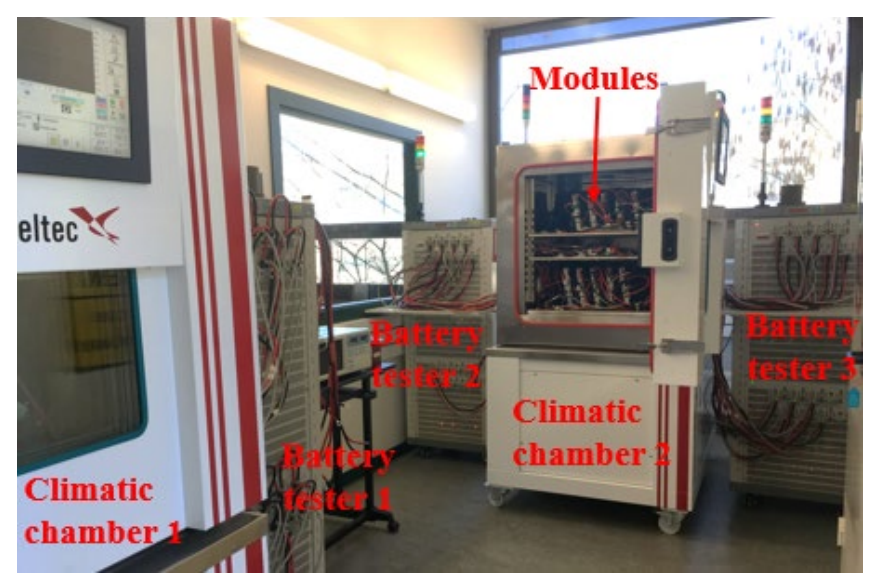

Fig. 2. Test bench used for module characterization. 
TABLE II. CAPACITY MEASUREMENTS ON FL AND SL MODULES (AH)

\begin{tabular}{|c|c|c|c|c|c|c|}
\hline & \multicolumn{3}{|c|}{ SL module } & \multicolumn{3}{c|}{ FL module } \\
\hline & $\begin{array}{c}0.5 C \\
(22 \mathrm{~A})\end{array}$ & $\begin{array}{c}1 \mathrm{C} \\
(66 \mathrm{~A})\end{array}$ & $\begin{array}{c}1.5 \mathrm{C} \\
(99 \mathrm{~A})\end{array}$ & $\begin{array}{c}0.5 \mathrm{C} \\
(22 \mathrm{~A})\end{array}$ & $\begin{array}{c}1 \mathrm{C} \\
(66 \mathrm{~A})\end{array}$ & $\begin{array}{c}1.5 \mathrm{C} \\
(99 \mathrm{~A})\end{array}$ \\
\hline $5{ }^{\circ} \mathrm{C}$ & 38.1 & 36.4 & 31.3 & 62.1 & 61.8 & 61.5 \\
\hline $25^{\circ} \mathrm{C}$ & 42.3 & 41.7 & 41.2 & 63.7 & 63.4 & 63.2 \\
\hline $45^{\circ} \mathrm{C}$ & 42.6 & 41.8 & 41.3 & 64.6 & 64.1 & 63.8 \\
\hline
\end{tabular}

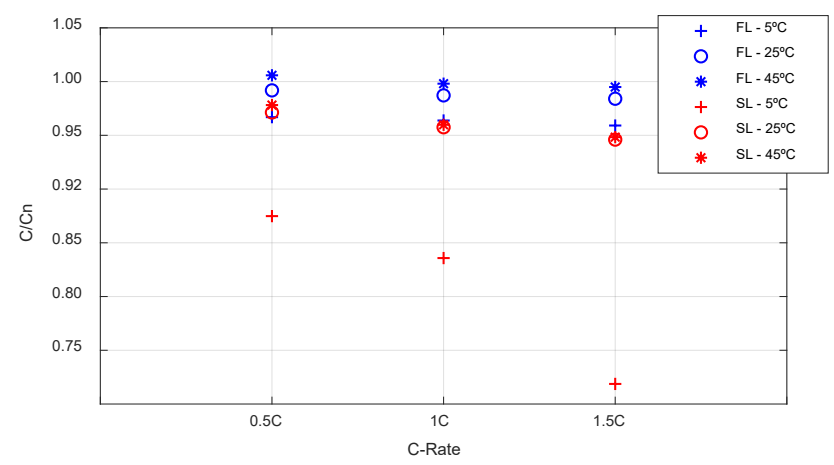

Fig. 3. Normalized capacity depending on discharge C-Rate for different temperatures $\left(5^{\circ} \mathrm{C}, 25^{\circ} \mathrm{C}\right.$ y $\left.45^{\circ} \mathrm{C}\right)$ for SL and FL module.

Moreover, as Fig. 3 shows, the worst capacity datum obtained corresponds to a discharge rate of $1.5 \mathrm{C}$ at a test temperature of $5^{\circ} \mathrm{C}$ for both modules. Nevertheless, the impact on capacity measurement differs. In the case of the FL module, the lowest value is a $95 \%$ of the normalized capacity, whereas on the SL module the differences are more significant, resulting in a value of around a $72 \%$ of capacity for high discharge currents.

\section{B. Influence of degradation on module performance}

Batteries operation is generally set according to voltage limits defined by the manufacturer. Nevertheless, as they age, the battery response to current changes varies due to the increase of its internal resistance, an effect that is more evident at high current rates. The reduction of the battery performance range affects directly to the energy that it can provide.

In this subsection the influence of temperature and discharge current rates on the operation voltage are analyzed for the FL and the SL modules. In general, performance differences on both module types are more marked at high currents. As an example, Fig. 4 shows the discharge voltage depending on the DOD (100$\mathrm{SOC}$ ) of the module, with a discharge current rate of $1.5 \mathrm{C}$, of a FL module (Fig. 4a) and a SL module (Fig. $4 \mathrm{~b}$ ), and for the three test temperatures $\left(5^{\circ} \mathrm{C}, 25^{\circ} \mathrm{C}\right.$ y $\left.45^{\circ} \mathrm{C}\right)$. The DOD is computed with reference to the nominal capacity value of each module. As Fig. 4 plots, there is hardly any difference for the test temperatures in the FL module, as at the end of discharge voltage $(5 \mathrm{~V})$ the DOD is always over a $95 \%$. However, for the SL module, the DOD is barely a $72 \%$ for low temperatures. This effect is compounded if the lower voltage limit is raised at low temperatures, as it is usually the case in some applications for security purposes. For instance, if the lower voltage limit is set to $6 \mathrm{~V}$, only a $21 \%$ of the DOD will be obtained for the SL module.

Another remarkable aspect is the discharge voltage shape depending on test temperature and current. As Fig. $4 \mathrm{~b}$ shows, at a discharge rate of $1.5 \mathrm{C}$ and $5^{\circ} \mathrm{C}$ the SL module voltage presents a different shape from that of the FL module (Fig. 4a). 

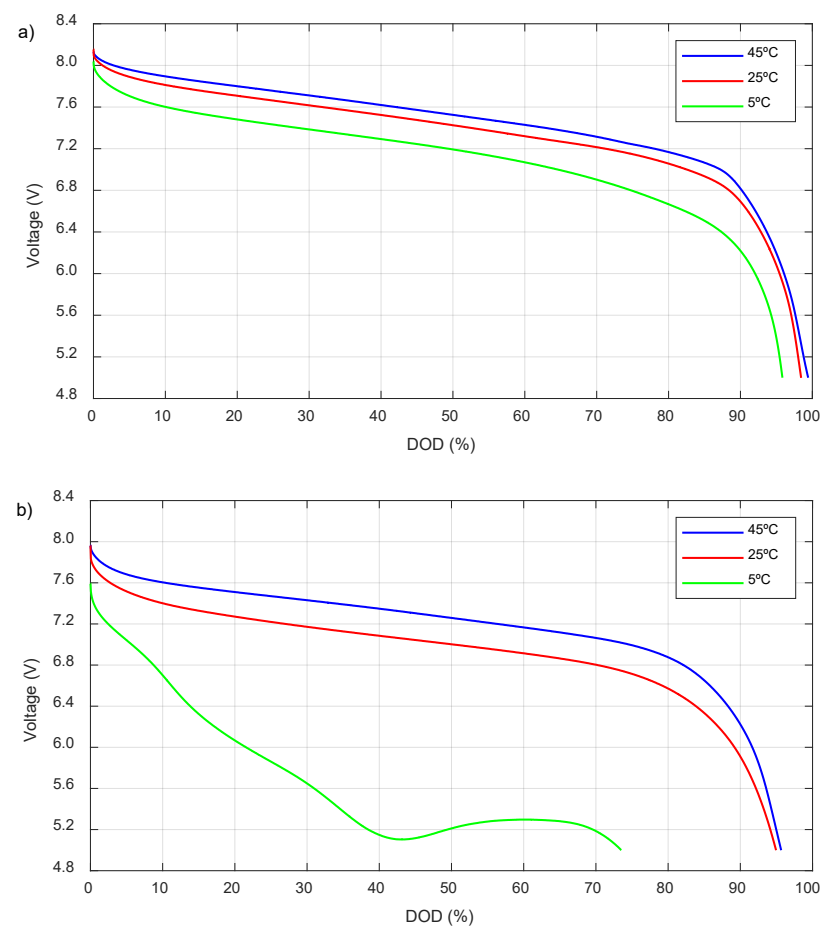

Fig. 4. Discharge voltage at $1.5 \mathrm{C}$ of a) $\mathrm{FL}$ module and b) a SL module for $5^{\circ} \mathrm{C}, 25^{\circ} \mathrm{C}$ and $45^{\circ} \mathrm{C}$ as test temperatures.

The internal resistance value of a module influences its voltage response to current steps. This resistance increases with aging, and therefore it is possible to see that the voltage drop at high temperatures is greater in the SL module than in the FL module, though their shape is similar in both cases. This is not the case at $5{ }^{\circ} \mathrm{C}$, where in the FL module there is the same tendency at all temperatures, while in the SL module the slope is greater and there is an intermediate knee. This behaviour is not observed in the rest of tested currents.

These operating voltage variations, along with the capacity decrease, have a direct impact on the energy delivered by the module. Analyzing energy variations for a given temperature depending on the C-Rate, the most significant difference is obtained at $5{ }^{\circ} \mathrm{C}$, with a $25.6 \%$ of difference in the SL module between the maximum (1.5C) and the minimum $(0.5 \mathrm{C})$ test currents. By contrast, at $45^{\circ} \mathrm{C}$ the maximum difference decreases to a $5.6 \%$ for this module. Once again, the impact on the FL module is considerably lower, with a maximum variation of $2 \%$ at $5{ }^{\circ} \mathrm{C}$ between the tested $\mathrm{C}$-Rates. In terms of energy, comparing with the value obtained at $25^{\circ} \mathrm{C}$ with $5 \mathrm{~V}$ as end of discharge voltage, the available energy on the FL module is slightly reduced to a $94 \%$, whereas on the SL module it falls to $65 \%$ for high currents and low temperatures.

\section{DISPERSION ANALYSIS}

In this section, an analysis of capacity dispersion on 32 SL modules and 10 FL modules of the Nissan Leaf is carried out. First, the internal dispersion (intra-module) of the module and in a second step the existing dispersion between modules (inter-module) are evaluated. Module capacity is measured according to the capacity test described in Section II.

\section{A. Intra-module dispersion}

As explained in Section II, each module consists of four cells in a $2 \mathrm{~s} 2 \mathrm{p}$ assembling, and has three external terminals (see Fig. 1). Capacity test is carried out in both $2 p$ superior cells and $2 p$ inferior cells. Fig. 5a shows the capacity obtained for the superior and inferior cells of the $32 \mathrm{SL}$ modules, whereas Fig. 5b represents the capacity differences between superior $\left(C_{s}\right)$ and inferior $\left(C_{i}\right)$ cells with respect to the mean capacity of each module $\left(C_{m}\right)$. The modules with greater differences between superior and inferior cells are module 28 , with 1.5 Ah, and module 16, with 1.2 Ah. These differences with respect to the mean capacity of each module imply a variation of a $3.39 \%$ and a $2.79 \%$ respectively. The lowest differences correspond to module 32 , with a $0.05 \%$ and module 2 , with a $0.11 \%$ with respect to their mean capacities.

Fig. 6 presents the existing dispersion on 10 FL modules. Fig. 6a shows superior and inferior cells capacity of each tested modules, and Fig. 6b plots capacity differences between superior and inferior cells, with respect to each module mean capacity. In module 5, superior cells capacity is $62.5 \mathrm{Ah}$, over $63.9 \mathrm{Ah}$ of the inferior cells, being this the greatest difference with respect to the mean capacity of the $10 \mathrm{FL}$ tested modules, with a $2.27 \%$. The lowest difference is that of module 6 , in which superior and inferior cells have practically the same capacity. 
Although the intra-module dispersion exists, it is not considerably important on the FL and SL modules. Moreover, since the cost of modules disassembling is not assumable, this heterogeneity is considered to be maintained on the battery packs assembled from these modules.

\section{B. Inter-module dispersion}

In this subsection, the capacity measured on the tested modules is compared among them, defining the existing dispersion. Fig. 7 shows the capacity of the 32 SL modules. The mean capacity value is $44.4 \mathrm{Ah}$, which corresponds to a $68 \%$ with respect to the nominal capacity of a FL module. The maximum capacity value is $47 \mathrm{Ah}$ and the minimum $42 \mathrm{Ah}$, which correspond to modules 32 and 7 respectively. This implies a total difference of $5 \mathrm{Ah}$, which is equivalent to an $11 \%$ of the mean capacity.
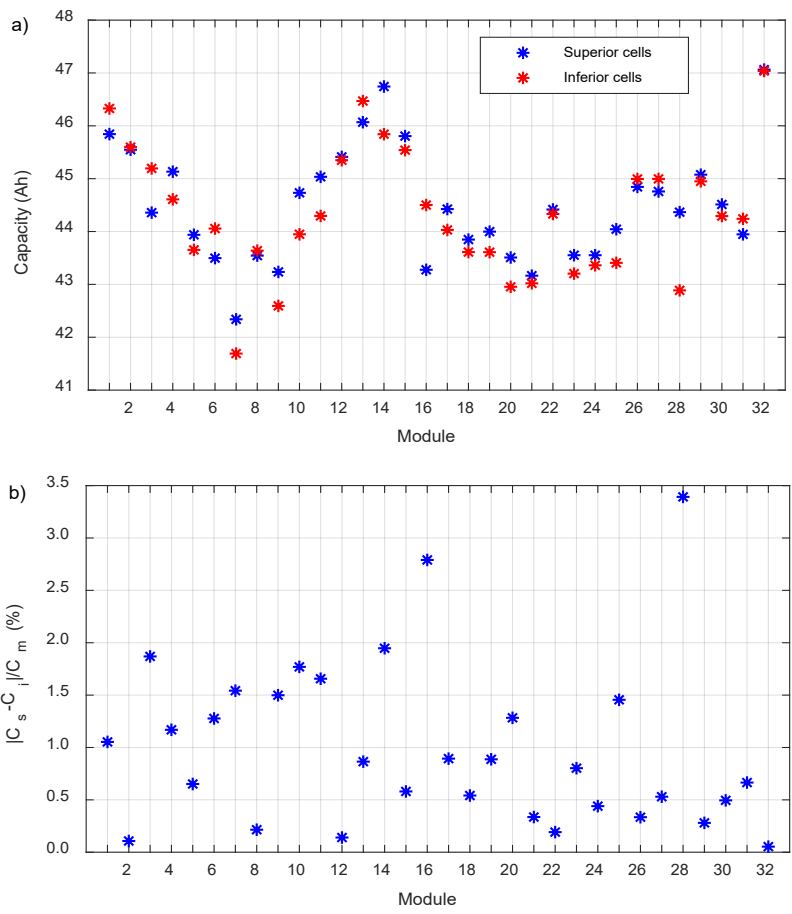

Fig. 5. a) Capacity of superior and inferior lithium ion cells and b) capacity differences between superior and inferior cells of 32 Nissan Leaf SL battery modules respect to mean capacity of the module.
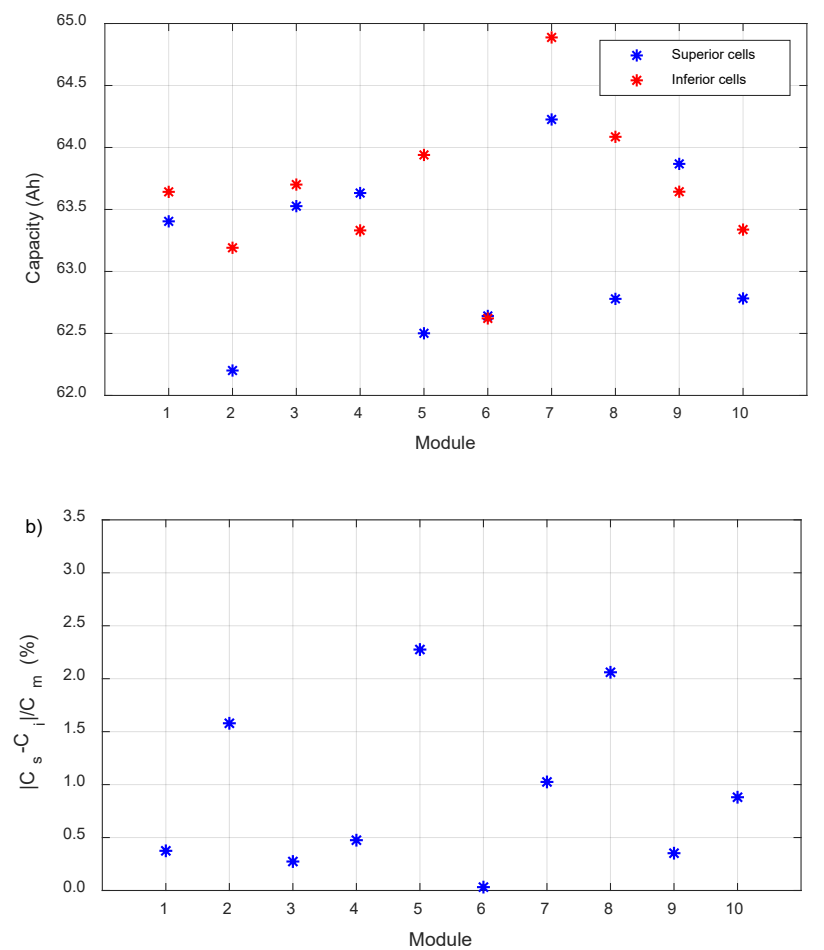
Fig. 6. a) Lithium-ion superior and inferior cells capacity and b) capacity differences between superior and inferior cells of 10 Nissan Leaf FL battery modules with respect to the mean capacity of the module.

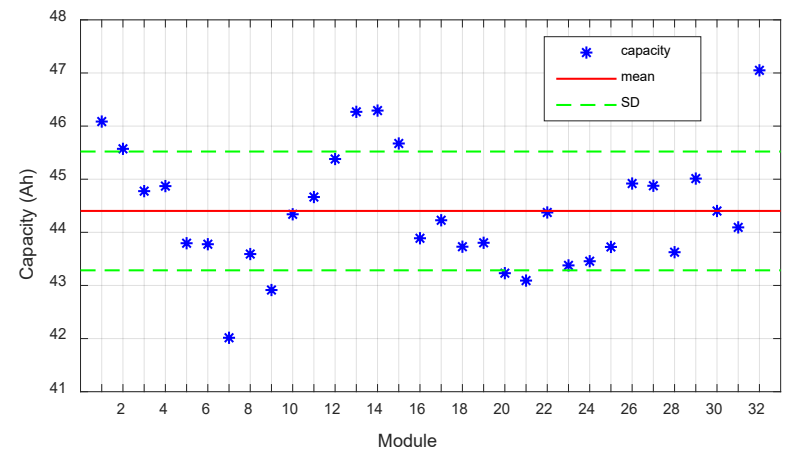

Fig. 7. Capacity of 32 Nissan Leaf SL battery modules.

Fig. 8 plots the capacity measured on 10 FL Nissan Leaf modules. The mean capacity of these modules is $63.4 \mathrm{Ah}$, with a maximum value of $64.5 \mathrm{Ah}$ from module 7 and a minimum value of $62.6 \mathrm{Ah}$ from module 6. The maximum difference is hence $1.9 \mathrm{Ah}$, which corresponds to a $3 \%$ with respect to the mean capacity.

\section{FL and SL batteries comparison}

Table III presents the results of both intra-module and inter-module dispersion analysis for FL and SL modules. Regarding intra-module dispersion, it is computed as the difference between superior and inferior cells with respect to the mean capacity of the module. Mean difference $\left(D_{\text {mean }}\right)$, maximum difference $\left(D_{\max }\right)$ and minimum difference $\left(D_{\min }\right)$ on the FL and SL modules are presented. Intra-module data are similar between FL and SL, with a $D_{\text {mean }}$ of $0.93 \%$ and a $0.99 \%$ respectively. Maximum dispersion is slightly greater on the SL modules (3.39\%) with respect to the FL (2.27\%). As the cost of cells disassembling is high, this dispersion has to be assumed in the formation of battery packs with both FL and SL modules.

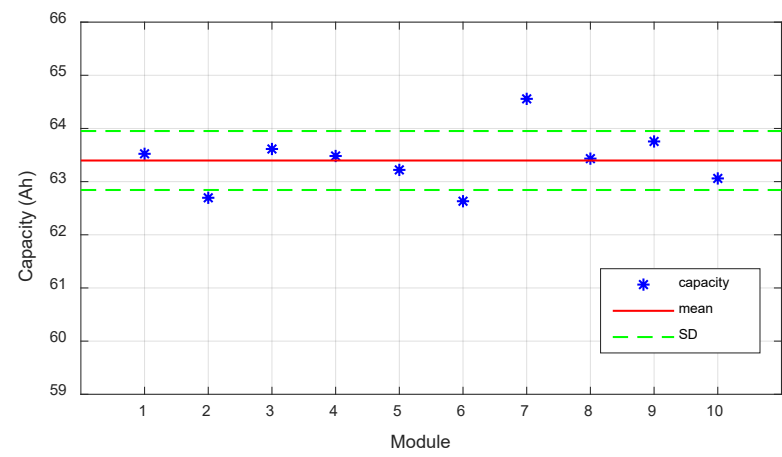

Fig. 8. Capacity of 10 Nissan Leaf FL battery modules.

TABLE III. FL AND SL MODULES DISPERSION

\begin{tabular}{|c|c|c|}
\hline & SL modules & FL modules \\
\hline \multicolumn{3}{|c|}{ Intra-module dispersion } \\
\hline Dmean (\%) & 0.99 & 0.93 \\
\hline Dmax (\%) & 3.39 & 2.27 \\
\hline Dmin (\%) & 0.05 & 0.03 \\
\hline \multicolumn{3}{|c|}{ Inter-module dispersion } \\
\hline Cmean (Ah) & 44.4 & 63.4 \\
\hline SD (Ah) & 1.12 & 0.58 \\
\hline CV & $2.52 \%$ & $0.91 \%$ \\
\hline Range (Ah) & 5.04 & 1.92 \\
\hline Range /Cmean & $11.3 \%$ & $3 \%$ \\
\hline
\end{tabular}


In order to analyze the inter-module dispersion, mean capacity $\left(C_{\text {mean }}\right)$, standard deviation $(S D)$, coefficient of variation $\left(C V, C V=S D / C_{\text {mean }}\right)$ and range are computed, this last one as the difference between maximum and minimum capacity with respect to mean capacity. Table III shows these values computed for FL and SL modules. A significant dispersion is obtained in the case of SL modules, with a difference of $11.3 \%$. However, for the FL modules this dispersion is considerably lower, namely of a $3 \%$.

Consequently, in the case of the assembly of battery packs with SL modules, capacity dispersion will affect negatively their performance if there is a random selection of modules. Moreover, the impact of this dispersion will lead to the reduction of the economic viability on SL modules reutilization.

\section{CONCLUSION}

This paper presents a detailed capacity characterization and a dispersion analysis centered on FL and SL Nissan Leaf modules.

Regarding characterization, temperature and discharge current have different impact on FL and SL modules. While capacity variation on FL module due to temperature for a given current is always lower than a $4 \%$, on the SL module it increases up to a $24 \%$ for high currents and low temperatures. On the other hand, for a given temperature, capacity variations lower than a $1.5 \%$ are obtained on the FL module. This value raises up to a $17.8 \%$ in the case of low temperatures and high currents on the SL module. Another considered aspect is the impact of module degradation on its performance. In the FL module, the voltage shape is similar in all cases whereas in the

SL module there are important differences at high currents and low temperatures. Because of these differences, the module arrives to the end of discharge voltage at only a $72 \%$ of its DOD.

In what dispersion analysis concerns, two levels are considered. First, it is referred to the existing dispersion inside the modules (intra-module), and in a second step with regard to the differences between modules (inter-module). For this purpose, 42 modules have been tested, 32 SL and $10 \mathrm{FL}$. Results show that there is not a significant intra-module dispersion neither in FL nor in SL modules. By contrast, in the case of the inter-module comparison, dispersion values observed are significantly higher in SL modules, with differences over an $11 \%$, whereas in FL modules the maximum corresponds to a $3 \%$.

To sum up, this contribution highlights that the correct use of SL modules from EV to reconfigure battery packs requires an adequate characterization. The main reasons are their significantly different behaviour with respect to FL modules and the greater dispersion between them.

\section{References}

[1] International Energy Agency / OECD, Global Electric Vehicle Outlook 2017, 2017.

[2] IEC 62660-1: Rechargeable Cells Standards Publication Secondary lithium-ion cells for the propulsion of electric road vehicles. Part 1:Performance testing, (2010).

[3] S. Saxena, C. Le Floch, J. MacDonald, S. Moura, "Quantifying EV battery end-of-life through analysis of travel needs with vehicle powertrain models", Journal of Power Sources, vol. 282, 2015, pp. 265-276, ISSN 0378-7753.

[4] E. Martinez-Laserna, I. Gandiaga, E. Sarasketa-Zabala, J. Badeda, D.-I. Stroe, M. Swiweczynski, A. Goikoetxea. " Battery second life: Hype, hope or reality? A critical review of the state of the art" Ren. Sust. Enegy Rev., vol. 93, pp. 701-18, 2018.

[5] B. Williams, T. Lipman, "Analysis of the Combined Vehicle- And Post-Vehicle-Use Value Of Lithium-Ion Plug-In Vehicle Propulsion Batteries", University of Califronia, Berkeley - Transportation Sustainability Research Center, 2012.

[6] J. Neubauer, K. Smith, E. Wood, A. Pesaran. "Identifying and Overcoming Critical Barriers to Widespread Second Use of PEV Batteries", National Renewable Energy Laboratory, U.S. pp.23-62, 2015.

[7] U. Debnath, I. Ahmad, D. Habibi, "Quantifying economic benefits of second life batteries of gridable vehicles in the smart grid". International Journal of Electrical Power and Energy Systems, vol.63, pp. 577-587, 2014.

[8] A. Berrueta, J. Pascual, I. San Martin, P. Sanchis, A. Ursúa, "Influence of the Aging Model of Lithium-Ion Batteries on the Management of PV Self-Consumption Systems", in IEEE International Conference on Environment and Electrical Engineering and IEEE Industrial and Commercial Power Systems Europe, 2018.

[9] I. San Martín, A. Berrueta, P. Sanchis, A. Ursúa, "Methodology for sizing stand-alone hybrid systems: A case study of a traffic control system", Energy, 153, pp. 870-81, 2018.

[10] A. Berrueta, I. San Martín, P. Sanchis, A. Ursúa, "Comparison of State-of-Charge estimation methods for stationary Lithiumion batteries", in IECON Proceedings (Industrial Electronics Conference), pp. 2010-5, 2016.

[11] A. Berrueta, M. Heck, M. Jantsch, A. Ursúa, P. Sanchis, "Combined dynamic programming and region-elimination technique algorithm for optimal sizing and management of lithium-ion batteries for photovoltaic plants", Applied Energy, 228, pp. 1-11, 2018.

[12] A. Berrueta, A. Urtasun, A. Ursúa, P. Sanchis, "A comprehensive model for lithium-ion batteries: From the physical principles to an electrical model", Energy, 144, pp. 286-300, 2018.

[13] Final technical report: Sustainability Assessment of Second Life Application for Automotive Batteries (SASLAB), 2018.

[14] The ELSA consortium, "ELSA - Energy Local Storage Advanced system", 2016.

[15] T. Rogge, "SunBESSy - Battery Energy Storage System", Vattenfall, 2016.

[16] EATON, "Nissan and Eaton make home energy storage reliable and affordable to everyone with "xStorage", 2016.

[17] C. Curry, Lithium-ion Battery Costs and Market, Bloomberg New Energy Finance, 2017. 
[18] E. Martinez-Laserna et al., "Technical Viability of Battery Second Life: A Study From the Ageing Perspective", IEEE Transactions on Industry Applications, vol. 54, no. 3, pp. 2703-2713, 2018.

[19] S. Rohr, S. Müller, M. Baumann, M. Kerler, F. Ebert, D. Kaden, M. Lienkamp, "Quantifying Uncertainties in Reusing LithiumIon Batteries from Electric Vehicles2, Procedia Manufacturing, vol.8, pp.603-10, 2017.

[20] K. Lee, D. Kum, "Development of cell selection framework for second-life cells with homogeneous properties", International Journal of Electrical Power \& Energy Systems, vol. 105, pp.429-39, 2019.

[21] http://www.electricvehiclewiki.com/wiki/battery-specs/ 